\title{
The role of innovative approaches in aesthetic vocal performance
}

\author{
(iD) Jinyi Liu \\ School of Music Education, Shenyang Conservatory of Music, Shenyang, China \\ 592904987@qq.com \\ (iD) \\ Min Zhou \\ Music Academy, Zhejiang Normal University, JinHua, China \\ 563383707@qq.com
}

\begin{abstract}
Vocal art is a means of conveying the artistic content of a musical work through voice, sounds, words, and intonation. The key objective of the research is to study the role of innovative approaches required for the aesthetic vocal performance. The method of a sociological survey and the SWOT analysis were used to achieve the goal of the study. The study involved 60 students from the Shenyang Conservatory of Music. The role of new technologies in teaching singing was determined with the help of two methods: the methodology by Strelnikova and the methodology developed in the course of the study. It was found that an integrated approach to teaching vocal performance is more effective and allows learners to achieve great results. This is evidenced by the results of a sociological survey. The use of the methodology developed allowed $89 \%$ of the participants to obtain high results two months after the beginning of training while only $77 \%$ of students improved their performance through the application of the methodology by Strelnikova. In addition, based on the SWOT analysis, strengths and weaknesses, as well as opportunities and threats were identified in the context of each method. The completeness of the data of the methodology developed has significant advantages for the aesthetic performance of songs. The results of the study will be useful for vocalists when building voices, as well as teachers when developing a curriculum.
\end{abstract}

Keywords: Choral singing. Beauty of music. Multi-voice singing. Breathing exercises. Repertoire. Timbre coloring. Voice range. 
Resumo: A arte vocal é um meio de transmitir o conteúdo artístico de uma obra musical por meio de voz, sons, palavras e entonação. O objetivo principal da pesquisa é estudar o papel das abordagens inovadoras necessárias para o desempenho estético vocal. O método de um inquérito sociológico e a análise SWOT foram utilizados para atingir o objetivo do estudo. O estudo envolveu 60 alunos do Conservatório de Música de Shenyang. O papel das novas tecnologias no ensino do canto foi determinado com a ajuda de dois métodos: a metodologia de Strelnikova e a metodologia desenvolvida no decorrer do estudo. Verificou-se que uma abordagem integrada para ensinar desempenho vocal é mais eficaz e permite que os alunos alcancem ótimos resultados. O uso da metodologia desenvolvida permitiu que $89 \%$ dos participantes obtivessem bons resultados dois meses após o início do treinamento enquanto apenas $77 \%$ dos alunos melhoraram seu desempenho com a aplicação da metodologia de Strelnikova. Além disso, com base na análise SWOT, foram identificados pontos fortes e fracos, bem como oportunidades e ameaças no contexto de cada método. A completude dos dados da metodologia desenvolvida traz vantagens significativas para o desempenho estético das canções. Os resultados do estudo serão úteis para vocalistas na construção de vozes, bem como para professores no desenvolvimento de um currículo.

Palavras-chave: Canto coral. Beleza da música. Exercícios respiratórios. Repertório. Coloração de timbre. Extensão vocal.

Submetido em: 31 de maio de 2021

Aceito em: 31 de julho de 2021 
The role of innovative approaches in aesthetic vocal performance Jinyi Liu • Min Zhou

\section{Introduction}

Music is one of the most accessible types of artistic creativity that contributes to aesthetic self-expression and the formation of the aesthetic culture of a person (DEMCHENKO, 2018; JACOBY and MCDERMOTT, 2017; RAVIGNANI et al., 2018). In the art of music, singing is of prime importance as it contributes to the formation of intonation, dynamic, and timbre hearing, as well as musical thinking and memory (GUO et al., 2020; HUOVINEN, 2021). Singing is also associated with the physiological characteristics of the body (breathing, blood circulation, endocrine system) and helps to get rid of stress (ASIF et al., 2019; NAWAZ et al., 2019).

The modern educational process, especially music teaching, requires the development and implementation of modern teaching methods, which should be preferred over traditional methods, which are gradually losing their popularity and effectiveness. European researchers emphasize the need to use such modern methods of studying music as machine-learning methods (KRAUSE et al., 2021). Instead, Chinese scientists prove the effectiveness of educational approaches, the essence of which is to use personalityoriented learning, development of professional competencies, improving creative skills, critical and reflective thinking, practice orientation (ZHUO and GUOFENG, 2021). The scientists from the USA propose the practical method of teaching with the use of modern technologies (SmartMusic, SingSnap, EarTrainer and YouTube) (SCHÜLER, 2020).

Undoubtedly, the major musical instrument is the voice, which is accompanied by vibrations of sound waves. Voice and breath training is an important stage not only in singing but also in voice formation. Therefore, at the early stage of development, children are taught to sing in kindergartens and schools, and later some of them choose singing as a profession (BERGEE et al., 2020). The major purpose of choral singing is teamwork, namely the ability to see, hear and listen to another person (DE BRUIN, 2018). Choral 
The role of innovative approaches in aesthetic vocal performance Jinyi Liu • Min Zhou

singing requires perseverance to unleash creativity. The main task of the choral performance is the clear voice, which becomes a song piece. At the same time, when performing, the multi-voice members should look aesthetically pleasing, the performance should be smooth and deprived of mannerism. When singing, only $20 \%$ of the sound is directed to the external space, the rest of the sound waves vibrate the internal organs; therefore, it is important to observe the aesthetic principles of reproduction when performing. The art of singing, which contributes to the improvement of pronunciation and speaking, is, first of all, proper breathing (BARASHKOVA et al., 2019; JERDIMALIYEVA et al., 2018).

Correct vocal technology promotes physiological vocal performance and aesthetic performance. The teacher needs to develop clear instructions for voice training and the formation of singing skills, namely exercises to develop intonation, articulation, diction, breathing, rhythm, and the ability to sing notes.

Singing is a form of productive activity. For the aesthetic reproduction of musicaltexts, an integrated approach thatcontributes to the development of the emotional sphere, communication skills, and musical abilities is required. For effective work, it is necessary to provide breathing exercises, ensure chanting, onomatopoeia, singing, and constant rehearsals. The repertoire should be selected in accordance with the task set and become more complicated from course to course. There are various approaches based on the formation of aesthetic singing according to which the performance of sounds in speech and singing is different (GORBUNOVA, 2020; LAWSON-ADAMS and DICKINSON, 2020; OKORO and OFUANI, 2020). This is due to the fact that in the colloquial speech the exhalation is not noticeable, and when singing it should be clear but not pronounced as the purity of singing depends on this. For example, [a] is close to [o], [u], and also tends to [o], [e]. This occurs in the high range as the formation of such sounds requires open oropharyngeal space.

For the naturalness of the formation of a vocal phrase, it is necessary to solve two problems of vocal activity: conscious control of the formation of speech sounds at a certain pitch and 
The role of innovative approaches in aesthetic vocal performance Jinyi Liu • Min Zhou

preservation of the text melody, which assumes a specific tempo, rhythm and emotional component of the process. Solutions to these problems are at the heart of vocal speech.

The purpose of the research is to study existing approaches to the formation of purity and beauty of performance, as well as to develop a new technique that will be significantly effective for the aesthetic reproduction of vocal singing.

The research objectives are to analyze the effectiveness of innovative approaches in the aesthetic vocal performance; on the basis of the results to determine the peculiarities of the integrated approach to teaching vocal performance; with the help of the SWOT analysis to single out and characterize the features of breath building.

\section{Research methodology}

To consider the role of innovative approaches in the aesthetic perception of vocal singing, a study based on a random distribution of participants was conducted. The study was carried out in 2020; it involved students of the Shenyang Conservatory of Music. Two groups of participants were selected and divided into two multi-voice Groups. Multi-voice singing Group No. 1 followed the method by Strelnikova, which is based on the correct provision of air exchange in the lungs, which is achieved with the help of short breaths through the nose during passive exhalation (SHCHETININ, 2009).

The participants of multi-voice singing Group No. 2 were trained in accordance with the methodology described in the study, which is based on an integrated approach and aimed at achieving beautiful musical reproduction. The control group consisted of 60 people (the distribution into groups is shown in Table 1). These participants were chosen as well as the main criterion was the presence of a musical voice and a satisfactory state of health, as it was necessary to measure the performance of the voice building. The process for 
The role of innovative approaches in aesthetic vocal performance Jinyi Liu • Min Zhou

selecting respondents was more random, but took into account the peculiarities of the musical voice of potential respondents. The study involved first-year students of the Shenyang Conservatory of Music. Initially, 83 students were selected for the study, but 13 of them were suspended. There were 11 respondents having health problems (high blood pressure, headaches), which contradicts classes based on the methodology by Strelnikova; 2 people were suspended due to violation of the rules (they did not attend the first lesson). All participants were in the same conditions. The distribution of respondents into groups was exclusively at their request in order to ensure equal rights in the experiment.

To study the effectiveness of a particular methodology, a sociological survey was conducted, which made it possible to obtain primary data on the effectiveness of the program through written analysis (SHAPIRO, 2017).

The next step was the development of a SWOT analysis, which involved interpreting the information received and assessing the strengths and weaknesses, as well as threats and capabilities of each of the methods. SWOT analysis allows the identification of elements that can be strengthened and developed in the future (ZAGORODNIKOV, 2013). It is an analytical tool, which has no numerical indicators and time dynamics. This technique is applied to a specific situation; in the process of changing the indicators, reanalysis is required. It 's considered that SWOT analysis represents the indicators of strengths, weaknesses, opportunities, and threats that in the context of voice building can be realized as the process of integrated approach and includes both work with voice, repertoire, and psychological aspects of singing (PALOMARES et al., 2021). This method of SWOT analysis gives the opportunity for a comprehensive analysis of the musical voice at various levels. SWOT analysis can be used in different studies for the determination of four features strengths, weaknesses, opportunities, and threats.

Based on the analysis of previous research, 9 most important components that affect not only voice building, but also the aesthetics of reproduction were selected. These are: 
The role of innovative approaches in aesthetic vocal performance Jinyi Liu • Min Zhou

- development of biophysical and psychological aspects of singing;

- correct breathing;

- development of diction and articulation;

- chanting;

- improvement of speech and vocal techniques;

- selection of an appropriate repertoire;

- systematic training;

- continuous improvement;

- building the beauty of singing and development of stage performance skills.

The study describes a rationale for each element that influenced the innovativeness of the research. The methodology by Strelnikova was selected as a program for comparison as proper breathing which it is based on is an integral part of singing. This methodology was distinguished by limited techniques that have long been known around the world (SHCHETININ, 2009).

There were 30 people in each multi-voice group. The participants were equally divided in order to obtain the most accurate and transparent indicators. Table 1 shows the characteristics of the respondents.

Table 1. Distribution of participants in the sociological survey

\begin{tabular}{lll}
\hline Gender distribution & $\begin{array}{l}\text { Number of } \\
\text { No. 1 participants }\end{array}$ & $\begin{array}{l}\text { Number of } \\
\text { No. 2 participants }\end{array}$ \\
\hline Women & 17 & 14 \\
Men & 13 & 16 \\
Total & 30 & 30 \\
\hline
\end{tabular}


The role of innovative approaches in aesthetic vocal performance Jinyi Liu • Min Zhou

The data obtained after two months of training on the effectiveness of the methodologies are described below. The effectiveness of the developed methodology is much higher than that of the widely popular one.

The sociological survey data were processed in Microsoft Excel as this is a systematic method that requires visualization. This method facilitates problem solving. When composing questions, the questionnaires were coded to ensure the anonymity of the data. Also, the results were processed based on the SWOT analysis, which is a subjective method relying on specific data.

There is no violation of any ethical standards in the study. During the experiment, all the moral requirements associated with conducting sociological surveys were taken into account. During the study, the boundaries of students and teachers who took part in the experiment were not violated. All actions were aimed at obtaining specific sociological information, which made it possible to determine the effectiveness of the methodologies used. The sociological study was carried out within the framework of regulatory documents: International Code of Practice for Marketing and Sociological Research ICC / ESOMAR (2016), Declaration of Helsinki (1964).

All procedures performed in studies involving humans were in line with the ethical standards of the institutional and national research committee, as well as the 1964 Declaration of Helsinki and its later amendments or comparable ethical standards. Informed consent was obtained from all study participants.

To study effective approaches to artistic expression in singing, research was conducted at the Shenyang Conservatory of Music. The Research Institute of the Conservatory conducted an experiment to determine the effectiveness of the two methods. Due to the fact that it is proper breathing that contributes to the natural development of the voice, the first group of participants (multi-voice singing Group No. 1) followed the methodology by Strelnikova (SHCHETININ, 2009) using "Pat-a-cake", "Shoulder", and 
The role of innovative approaches in aesthetic vocal performance Jinyi Liu • Min Zhou

"Pump" exercises. These exercises train and develop muscles that contribute to sound production. The major focus is on inhaling so that the voice sounds not only smooth but also aesthetically pleasing. The study involved 60 students from the Shenyang Conservatory of Music. It was not possible to involve more students in the experiment as other groups of students studied according to the plan determined earlier.

The limitation of the study is due to the small number of sample, which is due to the requirement for a musical voice. In addition, the method chosen for the study requires a satisfactory state of health to obtain reliable measurement results.

\section{Research results}

Thirty members of the multi-voice singing Group smoothing their voice and the aesthetics of singing were surveyed to determine the quality of this methodology and achieve correct voice building (according to inner feelings) after two months of training (Figure 1).

Figure 1. The effectiveness of the methodology by Strelnikova according to the multi-voice singing Group members, group 1

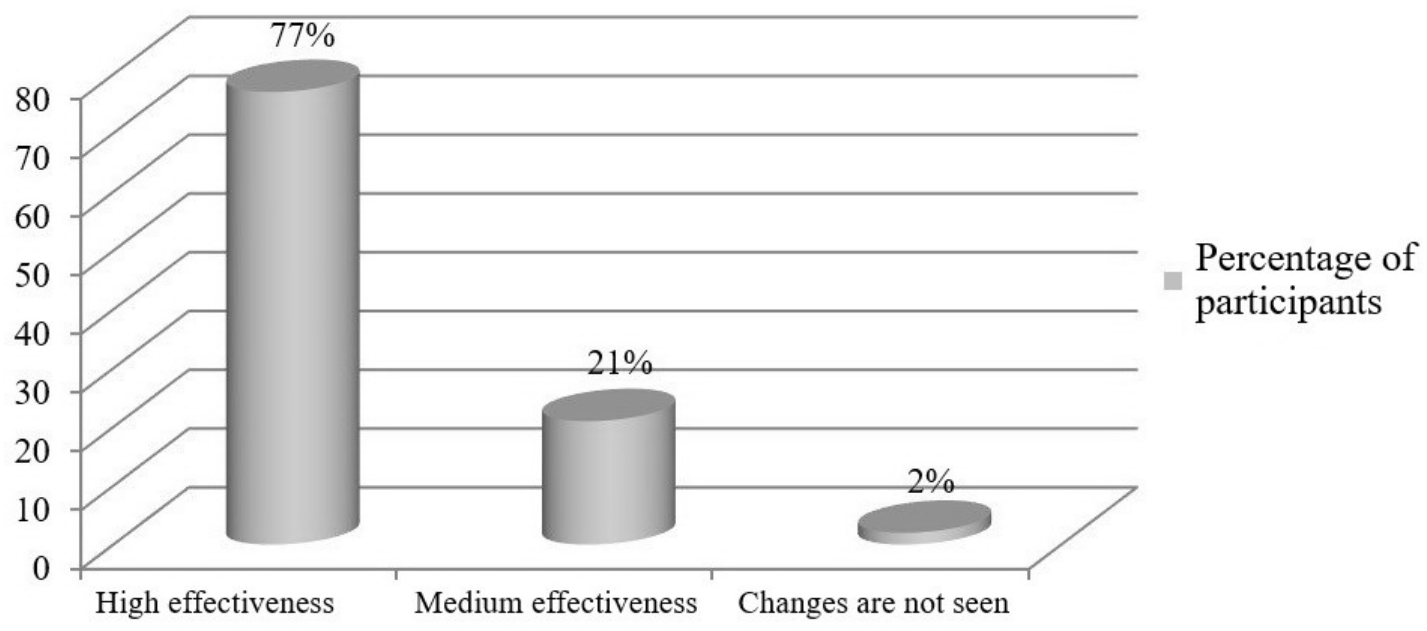


The role of innovative approaches in aesthetic vocal performance Jinyi Liu • Min Zhou

The figure shows that the majority of the participants (77\%) has high results after two months of training; $2 \%$ of the conservatory students surveyed hardly noticed any changes in the structure of their voices. This is due to the fact that each person needs a different amount of time to prepare.

The second group of participants (multi-voice singing Group No. 2) followed our own methodology. It is based on improving existing approaches (JELENA and MILICA, 2019; LYSENKO, 2018; SYDYKOVA et al., 2020) and introducing individual characteristics. We took a comprehensive approach to the development of a new methodology due to the fact that there are many factors affecting the aesthetics of singing and voice reproduction (correct breathing, correspondence of the repertoire, vocal technique, diction, articulation, etc.). The methodology of voice building and aesthetics of reproduction included three blocks (Figure 2). 
The role of innovative approaches in aesthetic vocal performance Jinyi Liu • Min Zhou

\section{Figure 2. The methodology of voice building and aesthetics of reproduction}

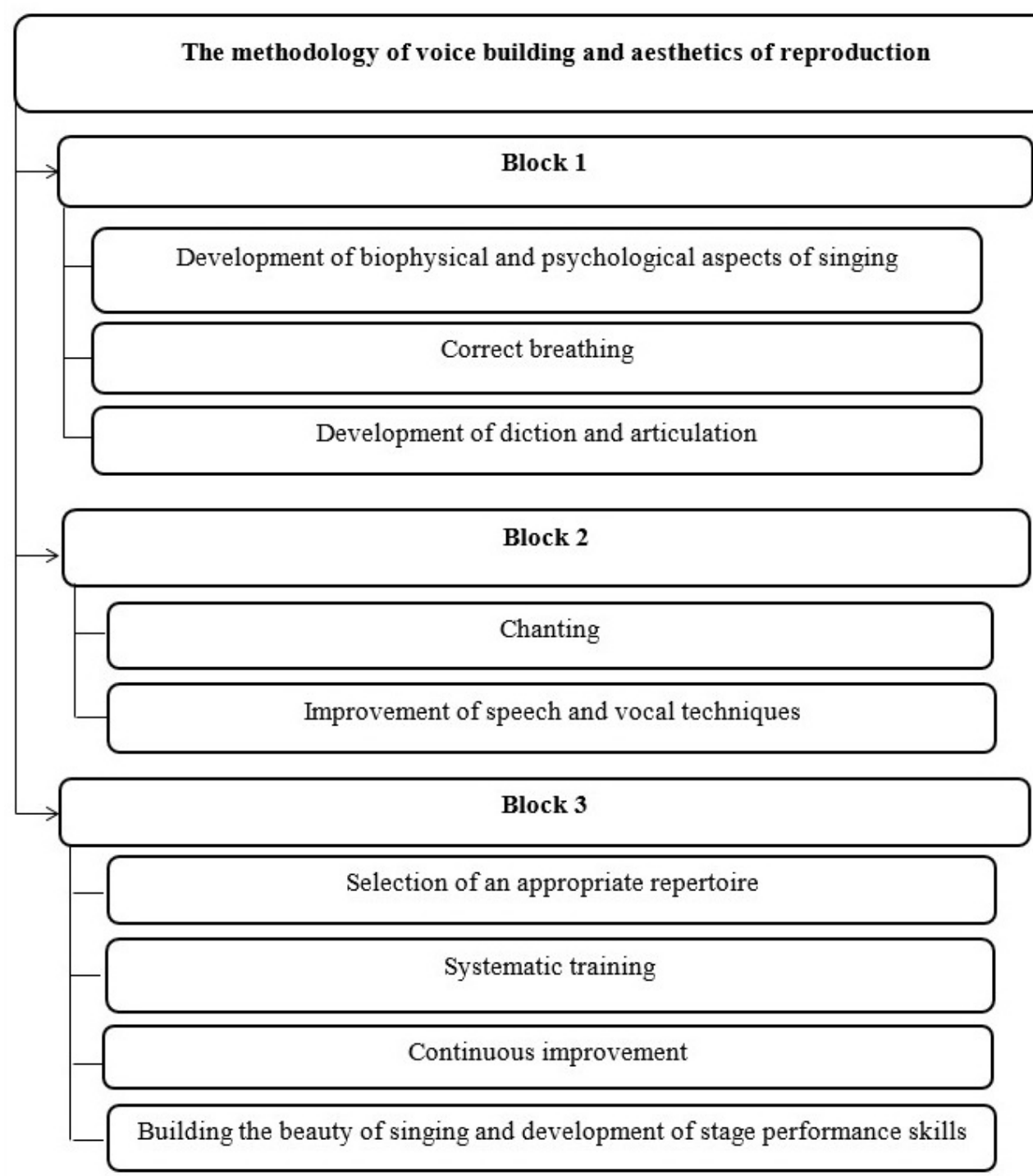

As mentioned above, the study involved 30 multi-voice singing participants. Initially, in accordance with the methodology we developed, the students were divided into timbre subgroups. The division into subgroups was required for the manifestation of the biophysical and psychological aspects of singing, development of diction and articulation, as well as building correct breathing. The first stage is as important as all other stages as it allowed us to identify the barriers that students face when singing, and to take further measures. At this stage, psychological voice development 
The role of innovative approaches in aesthetic vocal performance Jinyi Liu • Min Zhou

takes place and the physical activity of the performer manifests itself. At this stage, psychological barriers in singing and physiological problems are clarified due to the fact that it is possible to master singing only in a state of consciousness. Undoubtedly, singing is an arbitrary action, but mastering the secrets of the singing technique of voice formation is possible only when being mentally alert.

Diction is one of the important prerequisites for expressive and aesthetic performance. This element allows the performer to identify the major sounds and words and disguise the secondary ones. Clear diction was achieved through the following articulation exercises: light biting of the tip of the tongue; biting the tongue on the left and on the right; circular movements of the lower jaw; deep exhalation; tongue twisters. These exercises contributed to the correct development of the voice and pronunciation of words, the formation of clarity between diction and rhythm.

Since ancient times, vocal educators have had a rule saying that the art of singing is the art of breathing (MALLOCH and TREVARTHEN, 2018; SCHIAVIO et al., 2019). Diaphragmatic breathing is a key element in singing that contributes to the proper functioning of the larynx muscles. Both the purity of sound and the aesthetics of singing depend on it. Undoubtedly, the methodology by Strelnikova (SHCHETININ, 2009) is the most widespread; however, during the experiment, the main emphasis was placed on costoinferior breathing. When inhaling, the lower ribs expand while the rest of the chestremains motionless, and movements of the anterior abdominal wall are seen. Chest breathing was developed while lying on a rug on the floor. There is a second delay between inhalation and exhalation. The students were required to ensure that this pause naturally switches during singing from inhalation to exhalation; it should be imperceptible. The achievement of automatic performance and mastery of the technique of switching from inhalation to exhalation allows performers to get rid of grimaces, preserve naturalness, harmony and natural coordination when singing. Breathing was held with the stomach, and then followed by a calm and gradual distribution of exhalation while singing. 
The role of innovative approaches in aesthetic vocal performance Jinyi Liu • Min Zhou

The next stage was devoted to chanting. The teachers focused on vowel chanting to emphasize emotional expressiveness. Chanting should be thought out in detail taking into account the figurative-semantic and constructive side. Chanting required the participants of the timbre groups to repeat the following actions in a circle:

- vocal performance with a half-open mouth;

- focus on one syllable singing;

- whispering words;

- stop at a particular sound.

Chanting allows performers to develop expressive singing, figurative expression and quality performance. The chanting exercise was performed for 8 minutes for each subgroup, after which there was a pause of 1 minute and chanting continued for all members of the multi-voice singing.

The development of speech and vocal techniques is closely related to diction and articulation. Educators' research was aimed at the formation of vocal voice based on resonant singing techniques (BEGIĆ and ŠULENTIĆ BEGIĆ, 2018). The major emphasis was placed on the long sound "a" as it smooths the voice. During the study of vocal technique, the position of the larynx and articulatory movements of the vocal apparatus, the development of resonance of sound, the formation of a singing performance and the relationship with the quality of sound were considered.

During the development of the vocal technique, the participants of the experiment repeated various sounds and syllables, which made it possible to develop a speech apparatus. For example, the sound "rrrrr" made it possible to determine the upper resonator, and the sound "bssh" helped to develop the purity of the sound.

The selection of a repertoire is not only difficult but also time consuming. Multi-voice singing members who do not sing opera songs do not need to select a repertoire for a wide range of voices. The selection of a repertoire and voice development should occur 
The role of innovative approaches in aesthetic vocal performance Jinyi Liu • Min Zhou

on a simple-to-complex basis. Along with the development of vocal and technical skills, it is necessary to develop the beauty of singing. This should be done simultaneously in order to avoid unaesthetic singing in the future. During the rehearsals, there were activities directly aimed at the vocal apparatus development in accordance with the repertoire selected. The rehearsals made it possible to reveal nuances and details, as well as to expand the range of the voice. It is important to take into account that the repertoire in a foreign language causes additional difficulties in pronunciation and transmission of the text. Another language requires the performers to be more attentive, clearly pronounce the text and semantic accents, as well as understand the musical culture of another people. Therefore, not only Chinese sounds and phrases were taken as the basis for chanting, but also the peculiarities of other states were taken into account. The repetition of the multi-voice singing groups while singing in a foreign language made it possible to consolidate the correct articulation, reproduction of sounds, the proper rhythm, and memorize the melody. A step-by-step study of the material broken down into separate parts contributed to the achievement of the beauty of vocal reproduction. We believe that acquaintance with the melody is the primary stage as it helps study rhythmic transitions, highlight the change in the methods of sound intonation. Constant repetition of phrases made it possible to fix the position of the lips and other elements of the articulatory apparatus in order to obtain maximum aesthetic reproduction.

Continuous improvement was ensured through video recording of the rehearsals. The practice of each element allowed the performers to listen and control themselves into nationally adjusting their voices on high and low notes, identify difficult vocal pieces, develop clear diction and articulation. A personal approach to improvement made it possible to emphasize the individuality of each performer and identify their weaknesses.

Comprehensive work on the development of the beauty and aesthetics of the voice ensured high results. Among the participants of multi-voice singing Group No. 2, by analogy with the first group, 
The role of innovative approaches in aesthetic vocal performance Jinyi Liu • Min Zhou

a sociological survey was conducted to identify the effectiveness of the system (Figure 3).

Figure 3. The effectiveness of the innovative methodology according to the multi-voice singing Group participants, the second group

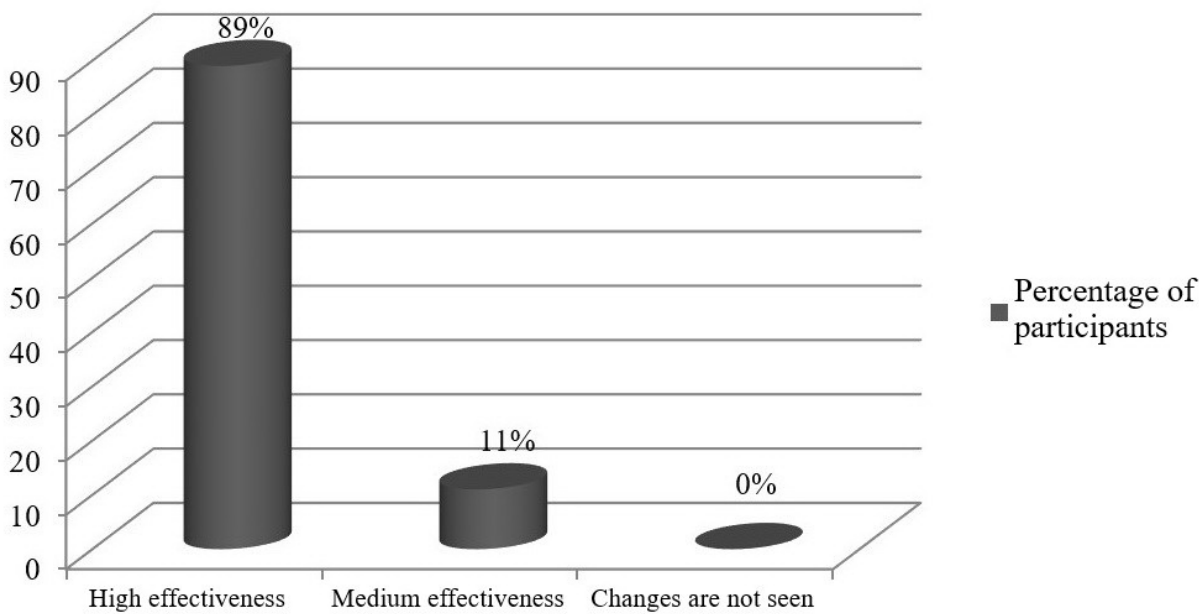

Based on Figure 3, the effectiveness of the singing aesthetics of the developed program is higher than the results of the first group as this methodology is based on an integrated approach. There is no doubt that proper breathing is an important element in singing, but singing beauty requires consistency. After two months of classes, the participants of the second group highlighted high (89\%) and medium (11\%) effectiveness.

After the final audition of multi-voice singing Group No. 1 and multi-voice singing Group No.2, the Shenyang Conservatory of Music Research Institute made their own conclusions about the effectiveness of the scientific experiment. The conclusions are described in the form of a SWOT analysis, which groups the research results: strengths, weaknesses, opportunities and threats of the methodologies used (Table 2 ). 
Table 2. SWOT analysis of the methodologies used

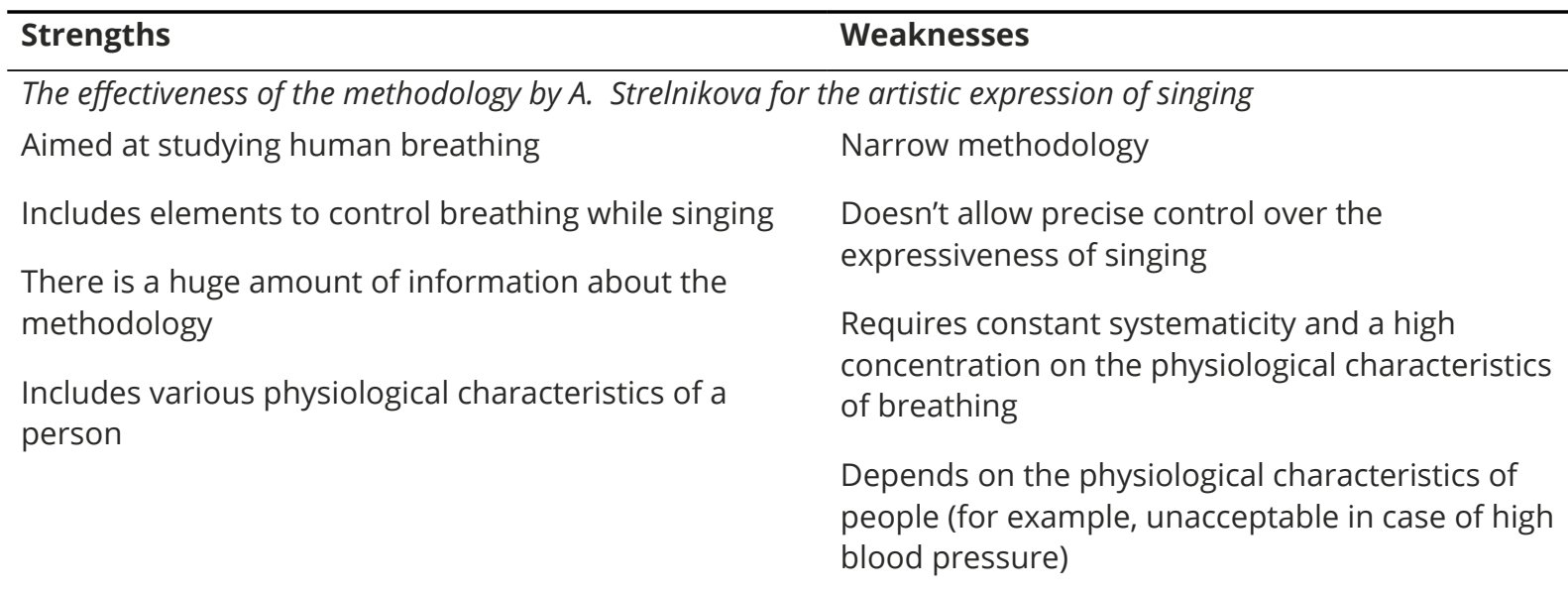

The effectiveness of our methodology for the artistic expression of singing

The methodology is based on an integrated approach and includes both work with voice, repertoire, and psychological aspects of singing

Developed specifically for the aesthetic vocal performance

The effectiveness of the methodology depends on the elaboration of three stages and an individual approach to the selection of the repertoire, rehearsals

The methodology includes continuous improvement, which is based on visual interpretation of rehearsals

\begin{tabular}{|c|c|}
\hline Opportunities & Threats \\
\hline \multicolumn{2}{|c|}{ The effectiveness of the methodology by A. Strelnikova for the artistic expression of singing } \\
\hline $\begin{array}{l}\text { It can be used both for building correct breathing } \\
\text { while singing, and for medical purposes }\end{array}$ & $\begin{array}{l}\text { It is not possible to control the correctness of the } \\
\text { exercise at a high level }\end{array}$ \\
\hline Can be used in case of speech impediment and & There is no comprehensive approach \\
\hline $\begin{array}{l}\text { There is a possibility of introducing more complex } \\
\text { exercises }\end{array}$ & $\begin{array}{l}\text { The main task is to learn to breathe properly; } \\
\text { however, it is not aimed at the musical beauty of } \\
\text { reproduction, which can affect the aesthetics }\end{array}$ \\
\hline $\begin{array}{l}\text { Increases the performance of the multi-voice singing } \\
\text { Group participants }\end{array}$ & $\begin{array}{l}\text { Lack of mechanisms for constructing accurate } \\
\text { indicators that affect the culture of choral singing }\end{array}$ \\
\hline \multicolumn{2}{|c|}{ The effectiveness of our methodology for the artistic expression of singing } \\
\hline $\begin{array}{l}\text { Various indicators can be modified } \\
\text { Psychological barriers in singing can be defined }\end{array}$ & $\begin{array}{l}\text { Lack of feedback on the results of the } \\
\text { effectiveness of the methodology }\end{array}$ \\
\hline $\begin{array}{l}\text { Diction and articulation are significantly developed, } \\
\text { which directly affects the aesthetics of singing }\end{array}$ & $\begin{array}{l}\text { Lack of scientific data on the consistency of the } \\
\text { sequence of steps }\end{array}$ \\
\hline $\begin{array}{l}\text { Increases the interest of the multi-voice singing Group } \\
\text { participants as it includes a diverse set of elements }\end{array}$ & \\
\hline
\end{tabular}

Lack of complete data on the methodology on the Internet

Breathing exercises are based on well-known

The methodology is more focused on the psychological state of a person rather than on the physiological one

Lack of feedback because the experiment was conducted only within one group methodologies
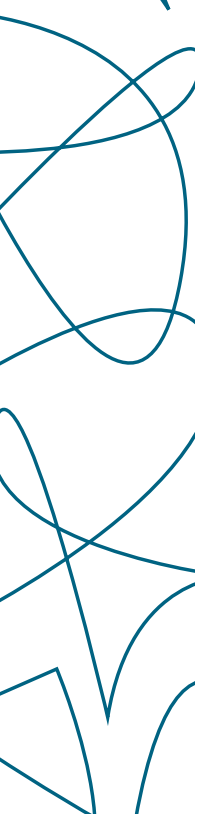
The role of innovative approaches in aesthetic vocal performance Jinyi Liu • Min Zhou

Based on the SWOT analysis, each methodology has its own characteristics, strengths, and weaknesses. However, the methodology we developed is aimed precisely at achieving aesthetic singing performance. It includes various elements aimed at developing the speech apparatus, the correct construction of the voice and the identification of psychological barriers.

After the final examination (two months after the beginning of training), the Shenyang Conservatory of Music Research Institute conducted an additional analysis of the effectiveness of the methodology developed. Each element of the methodology was evaluated based on visual perception. The results are shown in Figure 4.

Figure 4. The effectiveness of the elements of the methodology we developed:

1 - development of biophysical and psychological aspects of singing; 2 correct breathing; 3 - development of diction and articulation; 4 - chanting; 5 - improvement of speech and vocal techniques; 6 - selection of an appropriate repertoire; 7 - systematic rehearsals; 8 - continuous improvement; 9 - building the beauty of singing and stage performance skills.

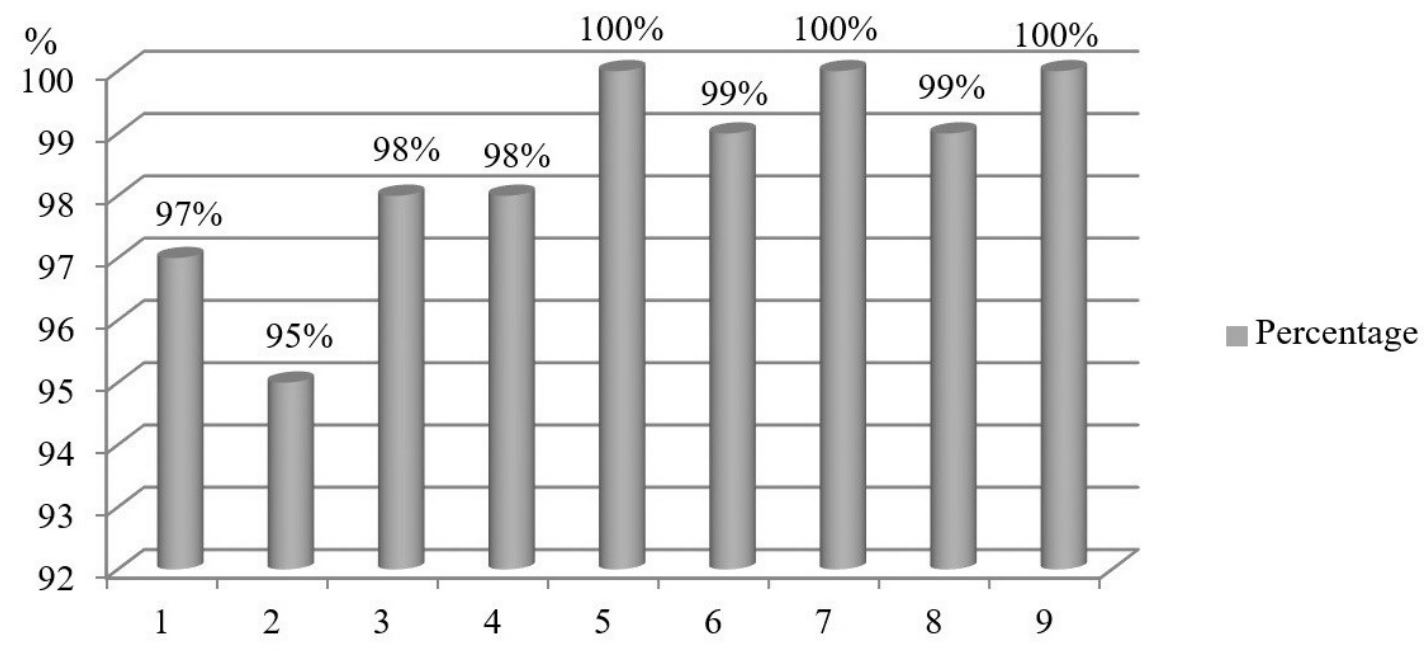

Based on Figure 4, according to the results of the research institute evaluation of the developed methodology, it was found that the participants of multi-voice singing Group No. 2 received the maximum efficiency (100\%) as the aesthetic singing performance 
The role of innovative approaches in aesthetic vocal performance Jinyi Liu • Min Zhou

was achieved. The lowest indicator is correct breathing (95\%) as at the final examination some of the students had minor problems with singing. However, it is possible to increase the efficiency of all indicators after a longer period of time.

\section{Discussion}

The mechanisms of pure reproduction of sounds and the aesthetic culture of singing have been considered by various scientists. Some of them studied the issues of correct breathing, others considered an innovative approach to chanting applied to one performer or the multi-voice. This study explores an innovative approach to aesthetic vocal performance based on two methodologies and substantiates the way a complex process affected the beauty of the performance of musical compositions. The work by BAKAR (2021) is focused on exploring innovative approaches to vocal staging, aesthetics, and singing improvisation among Malaysian singers.

The work by TÉLLEZ and VALLES (2020) shows that singing is essential in the practice of a musician, and outlines various ways of effective music teaching, which will be useful not only for the teacher, but also for the performer of popular music. The questions of homogeneity of timbre, types of breathing, phonetic accuracy have been studied taking into account the European academic traditions. Another study analyzes the relationship between the aesthetic implementation of plastic techniques and the emotional experience of the performer (DALSKAYA, 2020). The work by DALSKAYA partially overlaps with this study as it considers the psychological characteristics of the personality, which the key ones at the first stage of singing. However, in contrast to the research methodology we developed, the methodology by DALSKAYA (2020) applies to body plastics than to the speech apparatus.

The analysis of musical works by Salvatore Sciarrino was carried out in the study called Aesthetic and poetic in the music of 
The role of innovative approaches in aesthetic vocal performance Jinyi Liu • Min Zhou

Salvatore Sciarrino (CARDOSO FRANCO, 2019). The work presents paradigms about musical skill, aesthetic and philosophical concepts. The study by YUSHCHENKO et al. (2019) analyzed the scientific, pedagogical, musical and historical practices of teaching pop vocal, drew a parallel between the features of academic and pop vocal. The methodology we developed is not tied to a specific type of singing; it is based on the achievement of aesthetic voice performance, which is possible not only due to an integrated approach, but also special improvements.

The research discussed that performing songs in another language is a rather complicated process as it requires more concentration and time to study timbre and sounds. The study by DE FREITAS LIMA and MACHADO (2019) focuses on the ethnographic aesthetics of the voice. The authors studied the semiotics of the voice, which, in their opinion, affects the emotionality of the voice, and also analyzed the instruments that affect a change in the voice. As a result, a tool that promotes positive change for people who have voice disorders has been developed. The study by SHUWEN (2018) shows the differences between female and male vocals, provides an analysis of regional, ethnic, and class formations of gender identity of female performers.

BICKNELL (2018) describes the study in terms of expressiveness and loudness of singing. The study examines the issues of overaction of pop performers from the aesthetic and moral perspectives. The major conclusion is that performers need to be mindful of their expression, which should not attract the attention of the audience. The study focuses on comparing performances, but there is no technology making it possible to achieve high results.

The work by SZYSZKOWSKA (2018) shows the way ordinary everyday life affects musical art and its dependence on psychological aspects. The substantiation of the relationship between the aesthetic identity of oratorical and musical intonations of the ancient Greek theory of the musical system is studied in "Have the ancients notated the declamation? Aesthetic and anthropological participation in an enlightenment problem" (CÔTÉ, 2020). The 
The role of innovative approaches in aesthetic vocal performance Jinyi Liu • Min Zhou

authors argue that musical anthropology depends on genetic identity but not on a person. Based on computer visualization, DE OLIVEIRA (2019) found that sound depends on the phenomenon of listening. The complex use of art and digital technology is presented in a study by DA SILVA (2020), which allowed the use of mathematical software to create songs.

Research data show that many scientists were involved in the issues of voice, timbre, and musical aesthetics; they used innovative, computer, and mathematical technologies with the distribution to pop or classical vocals. In the study, the key focus is placed on the comparison of the well-known methodology by Strelnikova, which shows that breathing is the major element of singing, with the methodology we developed. An integrated innovative approach contributed to the fact that the methodology provided faster results in comparison with the methodology by Strelnikova based on the results of a sociological survey of respondents. In addition, the Shenyang Conservatory of Music Research Institute presented its findings, which are summarized in a SWOT analysis.

\section{Conclusions}

Singing is an important element of emotional and musical development; it helps develop an ear for music and thinking. The vocal should sound not only pure, but also be aesthetically pleasing when being performed; therefore, it is important to find an individual approach to an individual performer, ensemble, and multi-voice. In the formation of musical aesthetics, special attention should be given to working on the vocal apparatus, the correct pronunciation of words and sounds, and the observance of the musical timbre.

In the study, through the analysis of the two methods used by the participants of multi-voice singing Group No. 1 and multivoice singing Group No. 2, the role of new technologies and their 
The role of innovative approaches in aesthetic vocal performance Jinyi Liu • Min Zhou

effectiveness in aesthetic voice reproduction was established. A comparative analysis of the methodology by Strelnikova and the methodology we developed revealed their shortcomings and advantages. Two months after the beginning of training, a sociological survey was conducted among the participants of the two groups, which made it possible to determine the effectiveness of the results obtained and the task set. It was determined that in multi-voice singing Group No. 1, high efficiency was observed in $77 \%$ of the respondents while $2 \%$ did not see any changes. In multi-voice singing Group No. 2, 89\% of participants noted good results, there were no participants who did not notice any changes. This is due to the fact that the methodology by Strelnikova was based exclusively on the construction of breathing, which does not allow developing all the elements for aesthetic singing. The methodology we developed was based on an integrated approach. It included the development of the biophysical and psychological aspects of singing, diction, articulation, correct breathing (as one of the elements of the methodology by Strelnikova), chanting, speech and vocal techniques, careful selection of the repertoire, rehearsals, improvements and the ultimate goal of building the beauty of singing and skills of stage performance.

Also, in the study, the strengths and weaknesses of the methodologies, as well as opportunities and threats were identified by the Shenyang Conservatory of Music Research Institute; these were summarized in a SWOT analysis. It was found that in the same period of time (two months), a lesson according to the developed methodology made it possible to achieve great results. The SWOT-analysis showed that the strengths of classes based on the methodology by A. Strelnikova are aimed at studying human breathing; the methodology is well known and is focused on the physiological characteristics of a person. Among the weaknesses, we can highlight the narrow focus of the methodology and the impossibility of the accurate control of the expressiveness of singing; it cannot be used in case of various physiological characteristics of people. The strengths of the methodology we developed include 
The role of innovative approaches in aesthetic vocal performance Jinyi Liu • Min Zhou

the fact that it is based on an integrated approach and individually designed to achieve the aesthetics of singing; in addition, visualization of rehearsals allows learners to introduce improvements. But at the same time, the technique was applied only within one group and therefore further research is required.

This study describes important components that influence the aesthetic reproduction of vocal singing. When designing programs, it is necessary to pay attention to the maximum number of elements that affect the aesthetics of singing. The research results will be useful for teachers and vocalists who want to achieve the maximum aesthetics of singing. The prospects for further research are represented by the opportunities of improving the methodology and expanding the experiments; the methodology can be used in the comparative study of different styles of music and the influence of modern approaches on the effectiveness of the teaching of music.

\section{References}

ASIF, Anum, MAJID, Muhammad, ANWAR, Syed Muhammad. Human stress classification using EEG signals in response to music tracks.

Computers in Biology and Medicine, v. 107, p. 182-196, 2019.

BAKAR, Mohd Azharabu. A differentiation of gifted and talented singers. Turkish Journal of Computer and Mathematics Education, v. 12, n. 3, p. 2926-2938, 2021.

BARASHKOVA, Elena V., DROBYSHEVA-RAZUMOVSKAYA, Liudmila I., DORFMAN, Leonid Y. Integrative musical psychology. Education and Science, v. 21, n. 2, p. 96-112, 2019.

BEGIĆ, Amir, ŠULENTIĆ BEGIĆ, Jasna. Intercultural competence of future music teachers: Social reality and/or need. Sociologija i Prostor, v. 56, n. 2 , p. 161-178, 2018. 
The role of innovative approaches in aesthetic vocal performance Jinyi Liu • Min Zhou

BERGEE, Martin J., TAST, Rebecca L., WHEELER, Beth. AQ analysis of judgments of centrality in music education courses of study. Bulletin of the Council for Research in Music Education, v. 225, p. 7-21, 2020. BICKNELL, Jeanette. Excess in art: The case of oversinging. Journal of Aesthetics and Art Criticism, v. 76, n. 1, p. 83-92, 2018.

CARDOSO FRANCO, Sergio Kafejian. Aesthetic and poetic in the music of salvatore sciarrino. Musica Hodie, v. 19, Article number e52805, 2019. CÔTÉ, Trierry. Have the ancients notated the declamation? Aesthetic and anthropological participation in an enlightenment problem. International Review of the Aesthetics and Sociology of Music, v. 51, n. 2, p. 165-184, 2020.

DA SILVA, Ricardo Scucuglia Rodrigues. On music production in mathematics teacher education as an aesthetic experience. ZDM Mathematics Education, v. 52, n. 5, p. 973-987, 2020.

DALSKAYA, Valentina A. Aesthetics of plastic embodiment of an artistic image in vocal art as an indicator of performing arts and a guide for the teacher. Musical Art and Education, v. 8, n. 4, p. 94-106, 2020.

DE BRUIN, Leon R. Apprenticing for creativity in the improvisation lesson: A qualitative enquiry. Teaching in Higher Education, v. 23, n. 1, p. 84-103, 2018.

DE FREITAS LIMA, Ricardo Alexandre, MACHADO, Regina. Vocal agency: Gestural mapping of contemporary Brazilian popular singing. Opus, v. 25, n. 3, p. 66-93, 2019.

DE OLIVEIRA, Andre Luiz Goncalves. For an ontology of sound as an ontology of listening: Critical to the fetish of representation in modern western music. Musica Hodie, v. 19, Article number e51678, 2019.

Declaration of Helsinki, 1964. Available at <https://pharm-spb.ru/docs/ lit/Declaration\%20of\%20Helsinki.pdf>. Accessed on 13 April 2021.

DEMCHENKO, Alexander I. Universal art studies: Theory and practice.

Music Scholarship, v. 3, p. 102-108, 2018.

GORBUNOVA, Irina B. The concept of music computer pedagogical education in Russia. International Journal of Advanced Science and Technology, v. 29, n. 6, p. 600-615, 2020. 
The role of innovative approaches in aesthetic vocal performance Jinyi Liu • Min Zhou

GUO, Minjian, SU, Hua, YUE, Lei. Ecology-focused aesthetic music education as a foundation of the sustainable development culture. Interdisciplinary Science Reviews, v. 45, n. 4, p. 564-580, 2020. HUOVINEN, Erkki. Theories of creativity in music: Students' theory appraisal and argumentation. Frontiers in Psychology, v. 12, Article number 612739, 2021.

International Code of Practice for Marketing and Sociological Research ICC / ESOMAR, 2016. Available at <https://www.esomar.org/uploads/ public/knowledge-and-standards/codes-and-guidelines/ICCESOMAR_ Code_Russian_.pdf>. Accessed on 13 April 2021.

JACOBY, Nori, MCDERMOTT, Josh $\mathrm{H}$. Integer ratio priors on musical rhythm revealed cross-culturally by iterated reproduction. Current Biology, v. 27, n. 3, p. 359-370, 2017.

JELENA, Cvetković Crvenica, MILICA, Jovanović. Transfer of musical abilities and possible reflections of teaching content. International Journal of Cognitive Research in Science, Engineering and Education, v. 7, n. 2, p. 87-98, 2019.

JERDIMALIYEVA, Ritta, ABELTAYEVA, Janel, ELUBAEVA, Marjan, AKHMETBEKOVA, Dauresh, IMASHEVA, Aigul, KUSAMETOVA, Gulsum. The phenomenon of musical art in the education of individuals. Journal of Intellectual Disability - Diagnosis and Treatment, v. 6, n. 3, p. 125-130, 2018.

KRAUSE, Michael, MÜLLER, Meinard, WEIß, Christof. Singing voice detection in opera recordings: A case study on robustness and generalization. Electronics, v. 10, n. 10: Article number 1214, 2021. LAWSON-ADAMS, Jessica, DICKINSON, David K. Sound stories: Using nonverbal sound effects to support English word learning in first-grade music classrooms. Reading Research Quarterly, v. 55, n. 3, p. 419-441, 2020.

LYSENKO, Yu S. Studying problems of art interpretation in music at university of culture. Higher Education in Russia, v. 27, n. 7, p. 124129, 2018.

MALLOCH, Stephen, TREVARTHEN, Colwyn. The human nature of music. Frontiers in Psychology, v. 9, Article number 1680, 2018. 
The role of innovative approaches in aesthetic vocal performance Jinyi Liu • Min Zhou

NAWAZ, Rab, NG, Jian Tong, NISAR, Humaira, VOON, Yap Vooi.

Can background music help to relieve stress? An EEG analysis. In:

Proceedings of the 2019 IEEE International Conference on Signal and Image Processing Applications, ICSIPA 2019, Piscataway: Institute of Electrical and Electronics Engineers Inc., 2019. p. 68-72.

OKORO, Justice Chukwudi, OFUANI, Sunday. The social responsibility and aesthetic efficacy of abigbo music. International Review of the Aesthetics and Sociology of Music, v. 51, n. 2, p. 275-300, 2020. PALOMARES, Iván, MARTÍNEZ-CÁMARA, Eugenio, MONTES, Rosana, GARCÍA-MORAL, Pablo, CHIACHIO, Manuel, CHIACHIO, Juan, ALONSO, Sergio, MELERO, Francisco J., MOLINA, Daniel, FERNÁNDEZ, Bárbara, MORAL, Cristina, MARCHENA, Rosario, PÉREZ DE VARGAS, Javier, HERRERA, Francisco. A panoramic view and swot analysis of artificial intelligence for achieving the sustainable development goals by 2030 : progress and prospects. Applied Intelligence, v. 51, p. 6497-6527, 2021. RAVIGNANI, Andrea, THOMPSON, Bill, GROSSI, Thomas, DELGADO, Tania, KIRBY, Simon. Evolving building blocks of rhythm: How human cognition creates music via cultural transmission. Annals of the New York Academy of Sciences, v. 1423, n. 1, p. 176-187, 2018.

SCHIAVIO, Andrea, VAN DER SCHYFF, Dylan, GANDE, Andrea, KRUSEWEBER, Silke. Negotiating individuality and collectivity in community music. A qualitative case study. Psychology of Music, v. 47, n. 5, p. 706721, 2019.

SCHÜLER, Nico. Modern approaches to teaching sight singing and ear training. Facta Universitatis, Series Visual Arts and Music (FU Vis Art Mus), v. 6, n. 2, p. 83-92, 2020.

SHAPIRO, Mark G. Classification of survey methods in sociology. Social Studies, v. 2, p. 51-58, 2017.

SHCHETININ, Mykhail N. Full course of breathing exercises Strelnikova. Moscow: OOO "Izdatelstvo AST", 2009.

SHUWEN, Qi. Her "vocal authority": The semiotic and cultural soundscape of Chinese female rock singers' voices in the late 1990s. Social Semiotics, v. 28, n. 3, p. 349-370, 2018. 
The role of innovative approaches in aesthetic vocal performance Jinyi Liu • Min Zhou

SYDYKOVA, Roza S., YUSSUPOVA, Adalyat A., BEREKESHEV, Galimzhan K., SMAILOVA, Torgyn A., KULDANOV, Nauryz T. Psychosocial foundations for pedagogical skills formation of future specialists in the special educational environment. Journal of Intellectual Disability Diagnosis and Treatment, v. 8, n. 3, p. 485-496, 2020.

SZYSZKOWSKA, Małgorzata A. Musical phenomenology: Artistic traditions and everyday experience. Avant, v. 9, n. 2, p. 141-155, 2018. TÉLLEZ, Daniel M., VALLES, Monica. Singing in popular music: Reflections on its approach and teaching. Oido Pensante, v. 8, n. 2, p. 185-206, 2020.

YUSHCHENKO, Natalia S., TRIFANOVA, Vera P., SHCHERBININA, Valentina M., KATS, Maria L., TSAREV, Denis V. Aesthetic and technological basis for synthesis of academic and pop vocal traditions in the aspect of musical pedagogy. International Journal of Innovative Technology and Exploring Engineering, v. 8, n. 12, p. 355358, 2019.

ZAGORODNIKOV, Andrey N. Public relations management in business. Moscow: Krokus, 2013.

ZHUO, Kong, GUOFENG, Liu. Popular music singing video teaching based on android mobile network and embedded system. Journal of Ambient Intelligence and Humanized Computing, in press, 2021.

\section{Publisher}

Federal University of Goiás. School of Music and Performing Arts. Graduate Program in Music. Publication in the Portal of Periodicals UFG.

The ideas expressed in this article are the responsibility of their authors, and do not necessarily represent the opinion of the editors or the university. 